\title{
Walking Makes the Brain More Creative and Heals Your Sorrows
}

\author{
Jesus Dueñas Becerra* \\ Department of Psychology, Member of the Center for Studies of the Archdiocese of Havana, Cuba
}

*Corresponding author: Jesus Dueñas Becerra, Department of Psychology, Member of the Center for Studies of the Archdiocese of Havana, Cuba.

Received Date: October 29,2019

Published Date: November 06, 2019

\section{Opinion}

Having a habit of taking daily walks can be one of the best workouts also for your central nervous system, and that conclusion is supported by the findings of biomedical studies carried out for this purpose. In addition, it can relieve pain and reverse depression, among many other benefits that walking for only thirty minutes a day. The results of a research undertaken by American researchers offer a scientific explanation in this regard. Creative thinking improves while a person walks and stays that way for a while, as well as relieves stress, reverses penalties and improves cardiovascular health. The findings of that inquiry showed that walking outdoors drives creative inspiration. The act of walking in itself, and not in the environment, was the main factor. Across the board, creativity levels were consistently and significantly higher for those subjects who walked, compared to those who had remained seated. Many people report that they have their best thoughts when walking; Finally, we may be taking a step or two, to find out why. Other research has focused on the fact that aerobic exercise protects long-term cognitive function. But, so far, there is no study that specifically explores the effect of non-aerobic walking on the simultaneous creative generation of new ideas and then establishes the comparison with sitting. The person who has a habit of using treadmills, and is in a closed place, who does not see the landscape or the vegetation, but a blank wall, even so he can have twice as many creative answers compared to a person who remains seated. There are multiple causes and bad habits that make the person act automatically, since the brain learns routines and is able to perform automatic responses. Therefore, that person becomes less creative and gradually lacks new neural connections, which can cause memory problems, and of course, unhappiness or lethargy. Finally, walking is a way of renewing the mind, as well as improving the state of bodily, psychic and spiritual health of the human being.

\section{Acknowledgement}

None.

\section{Conflict of Interest}

No conflict of interest. 